apuntesuniversitarios.upeu.edu.pe

Apuntes Universitarios, 2020: 10(3), julio-setiembre

ISSN: 2304-0335 DOI: https://doi.org/10.17162/au.v10i3.478

\title{
Tecnología para la formación temprana de resistencia al estrés en el sistema de prevención de la mala adaptación escolar de alumnos de primer grado
}

\section{Technology for early formation of stress-resistance in the system of school maladaptation prevention of first-graders}

\author{
Elena L. Grigoryeva ${ }^{1 \mathrm{a}}$, Irina V. Volkova ${ }^{2}$, Andrey N. Baranov ${ }^{3}$, Sergey I. \\ Aksenov $^{4}$, Elena V. Bystritskaya ${ }^{5}$, Oleg A. Musin ${ }^{6}$, Maria V. Lebedkina ${ }^{7}$ \\ Nizhny Novgorod State Pedagogical University, Nizhny Novgorod, Rusia ${ }^{1}$ \\ Nizhny Novgorod State Architectural and Construction University, \\ Nizhny Novgorod, Rusia ${ }^{2}$ \\ Volga State University of Water Transport, Nizhny Novgorod, Rusia ${ }^{3}$ \\ Nizhny Novgorod State Pedagogical University, Nizhny Novgorod, Rusia ${ }^{4}$ \\ Nizhny Novgorod State Pedagogical University, Nizhny Novgorod, Rusia ${ }^{5}$ \\ Nizhny Novgorod State Pedagogical University, Nizhny Novgorod, Rusia ${ }^{6}$ \\ Nizhny Novgorod State Pedagogical University, Nizhny Novgorod, Rusia ${ }^{7}$
}

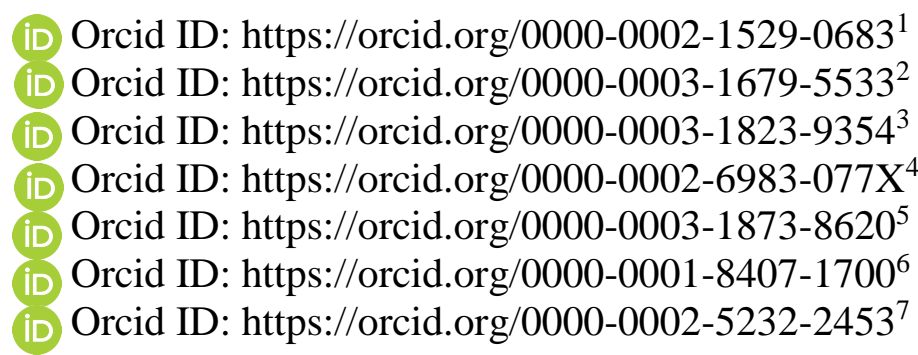

Recibido: 12 de enero 2020

Aceptado: 15 de mayo 2020

\section{Resumen}

La relevancia del problema declarado de la crisis de los niños de 6 a 7 años está dictada por la tendencia cada vez mayor de traer a los niños a las instituciones preescolares después de un corto período en la escuela por parte de los padres que notan la condición dolorosa del niño asociada con la mala adaptación escolar. En este sentido, muchos investigadores y educadores en ejercicio recomiendan revisar las fechas de inicio de los niños en la escuela para que el niño comience la escuela a la edad de siete años. Otros maestros notan un aumento significativo en la carga de trabajo de los escolares de primaria relacionados con la introducción del Estándar Educativo del Estado Federal para la Educación General Primaria y las formas correspondientes de actividades de control y evaluación. Por lo tanto, era necesario desarrollar nuevas tecnologías para preservar la salud de los estudiantes más jóvenes y permitirles superar la crisis del inicio de la educación. El propósito del artículo es describir la tecnología desarrollada destinada a ayudar a niños de 6 a 7 años a superar la crisis de la edad y prevenir la mala adaptación escolar 
con la ayuda de la formación temprana de tolerancia al estrés. El método principal en el estudio es el diseño de una tecnología para la formación temprana de tolerancia al estrés y la predicción de los resultados de su implementación en los grupos experimentales de niños de 6-7 años. La tecnología se basa en los principios de continuidad del proceso educativo entre las organizaciones educativas preescolares y las escuelas. Con la implementación de la tecnología desarrollada se lograron los siguientes resultados: mayor motivación para el éxito y un mayor nivel de salud somática manifestado en actividades deportivas y creativas. Los resultados mencionados a su vez contribuyeron a la prevención de crisis, la privación escolar de los alumnos de primer grado y la superación cómoda de la crisis de los niños de 6 a 7 años. Los materiales del artículo pueden ser útiles para los organizadores de actividades deportivas y creativas en instituciones educativas preescolares, educadores de grupos preparatorios, maestros, metodólogos en educación preescolar y primaria, así como maestros de educación física y maestros de primaria. Los materiales del artículo se pueden utilizar en el sistema de formación avanzada de docentes de educación física y primaria, así como en la preparación de actividades profesionales en instituciones educativas preescolares y escuelas primarias de estudiantes de escuelas de formación de docentes y universidades.

Palabras clave: adaptación, mala adaptación escolar, la crisis del comienzo de la educación, tecnologías para la formación temprana de la tolerancia al estrés, la integración de la creatividad artística y la actividad motora, juegos intelectuales móviles y deportivos, deportes en el espacio educativo.

\begin{abstract}
The relevance of the stated problem of the crisis of 6-7-year old's is dictated by the recently growing tendency to bring back children to preschool institutions after a short period at school by parents who notice the child's painful condition associated with school maladaptation. In this regard, many researchers and practicing educators recommend reviewing the start dates for children at school so that the child starts school at the age of seven. Other teachers notice a significant increase in the work load on primary schoolchildren connected to the introduction of the Federal State Educational Standard for Primary General Education and the corresponding forms of control and assessment activities. Thus, there was a need to develop new technologies to preserve the health of younger students and allow them to overcome the crisis of the onset of education. The purpose of this article is to describe the developed technology aimed at helping 6-7-year old to overcome the age crisis and prevent school maladaptation with the help of early formation of stress tolerance. The main method in the study is the design of a technology for early formation of stress tolerance and prediction of the results of its implementation in the experimental groups of 6-7-year-old children. The technology is based on the principles of continuity of the educational process between preschool educational organizations and schools. With the implementation of the developed technology the following results were achieved: increased motivation for success and higher somatic health level manifested in sport and creative activities. The above-mentioned results in their turn contributed to crisis prevention, school deprivation of first graders and comfortable overcoming of the crisis of 6-7 year olds. The materials of the article can be useful to organizers of sport and creative activities in preschool educational institutions, educators of preparatory groups, teachers, methodologists in preschool and primary education, as well as physical education teachers and primary school teachers. The materials of the article can be used in the system of advanced training of teachers of physical education and elementary school, as well as in the preparation for professional activities in preschool educational institutions and elementary schools of students of teacher training colleges and universities.
\end{abstract}

Keywords: adaptation, school maladaptation, crisis of the beginning of education, technologies for early formation of stress tolerance, the integration of artistic creativity and motor activity, intellectual mobile and sport games, sports in education space. 


\section{Introduction}

The study at school is a significant period in a person's life, during which knowledge basis that determines the further educational and professional path is formed, abilities and inclinations are actualized, a personality in a team is formed, the foundations of a worldview, beliefs, life principles are laid. In the formation of the student's personality, a significant place is taken by the process of involving them in different types of educational and creative groups, as well as engaging them in a large number of socially approved types of activities, among which a significant role is played by sport activities and educational work of the fitness sector (Mukhina, 1990; Maltsev, 2019). At the same time, the means of health-improving, corrective and health-saving technologies are practically not used to overcome the crisis of 6-7-year old's and their potential in solving this problem is not fully disclosed. In particular, the following aspect of the problem is poorly discovered: increasing the level of physical, mental and social health of students aged 6-7 by means of curriculum and extracurricular activities, as a basis for effectively overcoming by a child the crisis of the given age.

Underestimation of the importance of the additional education system in the formation of congruent three-component health of a schoolchild and the incorrect perception of the potential of this system leads to a mismatch in the development of the child's physical, mental and personal spheres and, as a result, to a decrease in immunity and an increase in morbidity (Busygina, Archipova \& Firsova, 2018; Abisheva, 2014). For example, some parents, striving to reveal and develop the maximum number of abilities and talents of a child, at the time of their admission to school simultaneously organize for the child classes in a full scope of clubs and teams. In this case, the consequences for school adaptation can be fatal. So, the child will have to adapt at the same time in educational, creative, sports teams and informal groups. In addition, the child masters fundamentally different types of activities. It all leads to an increase of the tension of the day (Krylova, 2017; Schlykova, 2015). The result is overwork and failure in certain types of activities and further demotivation of both the educational process and creative activities. Even more severe consequences arise when the child does not have sufficient abilities and inclinations for those types of creative activities chosen by their parents (Voronkina, 2016).

The other extreme of the child's parenting at school is that all family members begin to help the child, perform some types of work for them, show false pity and free the first grader even from the types of duties that he/she able to perform. The consequence in this case is the formation of late infantilism, and a negative attitude towards the school, where the child is loaded with various activities. Naturally, as the authors point out, adaptation to the conditions to which the child and his parents have negative attitude is extremely difficult. As research shows, it is this second of these categories of parents that most often initiates the return of a child to preschool education and then re-enrollment in school at an older age.

There is a number of successful technologies for adapting a first grader in a state of crisis 
of 6-7 years to the conditions of school studies. Among them: the theory of problematic training developed by the authors, the technology of adhering to the measure of learning difficulties, the technology for solving inventive problems (TRIZ) (Afonaseva, 2016), the technology of collective mutual learning (Kozubtsov, 2018; Selevko, 2005), heuristic learning technology adapted to the conditions of the child's start of schooling (Efimov, Kiseleva \& Nikitskaya, 2018), which, like the TRIZ technology, makes the learning process vivid and interesting, allowing to show various talents in the educational process. By and large, these and a number of other adaptation technologies have the following generalized characteristics:

1. All of them start the moment the child begins going to school and thus do not ensure the continuity of activities in the system of preschool education - school.

2. All of them to a large extent affect the child's intellectual characteristics, creative abilities, emotional positive perception of learning at school, but do not employ the potential of the additional education system to form the child's physical health as the basis for the success of any activity.

3. Most of these technologies are implemented in one permanent educational team and do not imply the possibility of expanding social interaction of the child with groups of different ages.

As follows from the above, the existing technologies for the prevention of a child's crisis in the period of preparation for school and the start of school, affect one of two, and not both, levels of education (pre-school and school). The indicated technologies are implemented, as a rule, in one of the forms of instruction, either in the classroom or outside the classroom. But they do not constitute an integral system aimed at formation of congruent health of schoolchildren. In addition, these technologies, with the exception of collective mutual learning technology, do not allow the child to be included in temporary educational and upbringing groups not connected to the permanent educational group. And this is one of the significant tasks of socializing and adapting the child to the system of new social roles and functions (Alekseeva \& Gregory, 2019; Bystritskaya et al., 2019b). Thus, the relevance of the study is confirmed by the need for new technologies for adapting first graders to the conditions of schooling. The new technologies should be based on the types of activities known to the child, on the principles of continuity, which set the task of improving the health of the child and implying the possibility of socially approved open interaction with different age groups of like-minded people approved activities (Runova, Gutsu, \& Nyagolova, 2019).

The aim of the article is to introduce the technology of early formation of stress tolerance (EFST) in a preschooler and primary school student and the development of the potential for overcoming school maladaptation by them. To achieve this goal, the authors undertook an analysis of existing technologies for prevention and overcoming school maladaptation, including physical education classes. 
At the beginning of the study, the task was set to analyze the situation with the adaptation of children to the conditions of school studies and the characteristics of the level of manifestation of the crisis of 6-7 year olds in this process. The state of adaptation and maladaptation of children of six-seven years of age to the conditions of study at school was monitored. A dynamic increase in the tendency for longer periods of adaptation of the child to school and an increase in the severity of symptoms associated with the crisis of 6-7 years of age were revealed. Further, it was necessary to develop a technology that would facilitate the continuity of the levels of education of the child's interaction with different groups of people and simultaneously would solve the tasks of saving and correcting children's health. As such a technology, the technology of early formation of stress tolerance (EFST) was proposed. The EFST technology involves a combination of the individual educational trajectory of students and the development and implementation of programs with permanent and temporary teams of the same age and different ages. For the implementation of the developed technology, the following approaches were used:

1. System-activity, involves a combination in a single educational complex for all types of educational, creative, domestic and sports activities, aimed at harmonizing not only the knowledge and ideas of the child, but also their values, goals, interests, abilities and personal meanings. The main postulate here is: the activity that allows to show the abilities and interests of the child, is also the basis for their development (Sergei, 2016; Grigoryeva et al., 2019).

2. A collective approach to education, which in relation to the principle introduced by A.S. Makarenko on "Reliance on the positive in education" requires the inclusion of the child in the pre-crisis and post-crisis periods of development in the maximum number of diverse socially positive groups, including groups of different ages. The inclusion of the child in such groups to perform artistic and sports activities allows them to develop multidisciplinary skills that enable them to comfortably join in new activities and flexibly, not anxiously and not aggressively respond to various requirements of different subjects of education (Dormidontova, 2016; Bystritskaya et al., 2019a).

3. A personality-oriented approach that allows to create an individual trajectory of a child, taking into account the individual unique potential of the student, their stable interests, physical abilities, hierarchy of motives and individual characteristics of the student. This approach allows us to consider the system of general and additional education, the system of family schooling, as well as the system of preschool and school education, as an integrated successive education of a child (Korenkova, 2015; Tymaseva \& Orekhova, 2019; Talebi, \& Nejad, 2019).

\section{Materials and Methods}

The following technologies were used in the study: comparative analysis of data on the 
presented phenomenon published by various authors; empirical research methods, among which the study of students' drawing tests; analysis of the results of projective and test methods on the research problem; methods of mathematical statistics, confirming the reliability of the data. At the stage of the forming experiment, the EFST technology was developed and implemented based on the principles of the SPART system introduced by V. I. Stolyarov (Joiners, 2017; Neverkovich et al., 2019; Vahedi, \& Arvand, 2019). In the experiment, artistic creative and physical activities were used in the system of general education of preschool children and additional education of younger schoolchildren. The technology of early formation of stress tolerance includes three stages:

1. A survey of the levels of physical and mental development, their social well-being, individual developmental characteristics and actualized interests and inclinations was held. Further, at the same stage, the level of pedagogical literacy of parents in the issues of upbringing, education and physical development of a child was studied. A survey of the infrastructure of educational organizations, the residence of children included in the experimental group was conducted in order to identify the presence and specificity of the centers of cultural and healthy leisure in the neighborhood on the basis of which it was planned to implement certain components of the technology.

2. A set of methods was developed aimed at increasing the level of stress resistance of preschoolers and schoolchildren in order to eliminate children's fears and aggressive manifestations. The methods are the following:

- Early introduction of sport (sportization) to the system of physical education of preschool children (SPARTIAN Academy, Brotherhood of the Ball) and other types of adapted competitions with the inclusion of creative, musical, artistic and other components presented in a competitive mode.

- A flexible system for evaluating the results of sports and creative activities, combining a rating system (winning prizes) and a nomination system (awarding nonalternative categories), simultaneously enhances the motivation for success and reduces anxiety before a possible failure in sports or creative activities. The situation of anxiety in this case occurs in a competition with the use of an "inverted" personal example, when children become a worthy example and guide for their parents and other adults with regard to their involvement in sports and creative activities, which creates an opportunity for children to grow up for real. Coming to school, such an "adult child" shows leadership qualities and strives for improvement in order to become a worthy example in a new team.

- The method of mastering and manifesting the principles of Olympism not only in sports, but also in other creative activities - fine art, choreography, music, folk crafts. 
For this, Olympic traditions and attributes associated with the observance of these principles are applied. The mastery of the principles of Olympism at early stages of general education by children at the SPARTian Academy sets the coordinates for the formation of the following groups of socially and personally significant qualities: strong-willed (independence, initiative, perseverance, determination), moral (honesty, responsibility, friendliness, goodwill), intellectual (curiosity, analytical abilities, creativity), as well as aesthetic ones (love for beauty, art, harmonious physical activity) (Gregory \& Borisenko, 2019). All these qualities are socially approved and increase the level of stress resistance of preschoolers and primary schoolchildren.

- The method of problem training, which is implemented in the competition mode for various types of physical activity, which have common features, for example, associated with handling different balls, volleyball, basketball, tennis, etc. In this case, children are confronted with specially organized difficulties and barriers, and then their success, especially in a team mode, leads to a willingness to overcome problems in their path. The motivation for achieving success and determination is formed.

- A method of didactic game in which children rehearse their social role functions and responsibilities in the school system. At the same time, children are allowed to change the roles of students and teachers several times per game.

- Communicative games where children are places in conditions of a certain social structure and carry out the quest task. This allows preschoolers to perceive environmental laws, adopt them at a non-conflict level and realize their abilities within the framework of these requirements of society, many of which, as practice has shown, they discover during the game for the first time.

- Interactive and multimedia games in the physical education of a preschooler and primary school student (Project "Sportlandia"). This is a method of interaction between all lovers of a particular sport, children and adults living in one micro-site. This method makes it possible to motivate children through showing worthy examples so that they consciously choose a sports club for themselves, which they can join before starting school. Such a child, coming to first grade, where a completely different children's team expects him, other responsibilities and requirements system does not feel any communicative discomfort, because outside school he has a stable team with an established relationship system - this is the team of their sports club. In addition, sports activities per se increase the level of stress resistance of a child, regardless of what kind of sport they are engaged in. 


\section{Results}

Development and implementation of the individual educational trajectory of the child, taking into account the results of their diagnostics and based on the above methods. Each trajectory includes mandatory points for the dynamic diagnosis of those indicators of the child that manifest a certain level of stress tolerance. From the point of view of physical health, such methods may include characteristics of physical fitness, the pace and effectiveness of mastering motor actions, as well as indicators of somatic health. As diagnostic methods for introducing stress resistance to preschoolers and schoolchildren, we can offer adapted methods such as "House, tree, person", "Non-existent animal" and others, as well as measuring motivation for success, the level of anxiety and conflict of the child. To identify the socio-personal component of stress tolerance, the reference groups of the child, their social roles, communication skills and the presence of leadership qualities are determined.

The following are the results of applying EFST technology in preschool educational organizations and schools in the Nizhny Novgorod region.

The proposed EFST technology was implemented in pre-school educational organizations and schools of the Nizhny Novgorod region several academic years in the period 2015-2019. The experimental base of the research provided DOU No. 134, Dzerzhinsk, MDOU No. 108, Dzerzhinsk, MBDOU No. 141, Dzerzhinsk, the combined type Ivushka, Bor, Oktyabrsky, and schools No. 7, Bor, No. 17 and No. 33, Dzerzhinsk. The experimental activity was carried out in an experimental group with a total number of 627 children aged 5 to 7 years. Implementation of the technology was carried out in each of the experimental groups for two academic years. The first year - in the preparatory group of kindergarten, the second year - in the first grade of school. A control group of 114 children was also allocated (5 kindergarten groups and 3 first grade groups). In the experimental group, the work was carried out using the abovementioned methods twice a week in a preschool educational institution, once a week in the first grade; and for younger students, three types of activity of the EFST technology were used. In educational activities, these methods were implemented by the class teacher or physical education teacher in the classroom. As part of the fitness activities, a school medical worker, a psychologist, a social teacher and representatives of the board of trustees were also involved in the work. As part of mass sports, this technology was supported by representatives of sports federations and sports and cultural facilities, athletes and veteran athletes, as well as representatives of the sports community.

In the control group, continuity and the child's adaptation to school activities during the crisis period of 6-7 years, was carried out in the framework of standard programs approved by the educational authorities of the appropriate level. The following criteria were selected as criteria confirming the increase in the efficiency of the technology aimed at overcoming the crisis of 6-7 years by children of preschool and primary school age: 
- reduction in anxiety;

- increasing the motivation for achieving success;

- $\quad$ an increase in the level of goals in educational and extracurricular activities;

- manifestation of communicative skills and building conflict-free communication;

- manifestation of leadership and strong-willed qualities;

- educational success at primary school age;

- $\quad$ sports success (based on expert assessment of the coach and teacher of PE);

- somatic health increase.

Measurements of these criteria were carried out at the beginning and at the end of each academic semester and made up the dynamics of 6 data. Analysis of the effectiveness of the activities of primary schoolchildren was carried out using the following criteria: level of claims, communication skills, leadership and strong-willed qualities, academic success, sports success, health status.

It became obvious that tangible results are achieved if health-forming technology aimed at including the child in the health-saving process is implemented with the coordination of the efforts of family and school, the health-improving technology itself, as well as the technology of developing a health culture using the educational potential of the family and the additional education system carried out continuously for two academic years as a support program for children undergoing the age crisis of 6-7 years. So the criteria for stress resistance, which include a decrease in the level of anxiety and aggressiveness, an increase in self-esteem of motivation and a level of claims have increased to the maximum level. This can be explained by the fact that early introduction of healthy competition in the lives of children can not only reduce maladaptation, but also prepare them for the most competitive teenage years. Indicators related to interaction and communication appeared second in value. It indicates the importance of engaging children in a variety of teams involved in creative activities, including those of different ages. Surprisingly, with the implementation of the developed technology which is directly related to health-formation the actual level of physical health and the level of physical culture and sports success of children has not changed significantly. An explanation of this phenomenon can be the following: physical health itself is more dependent on genetic and other factors that cannot be changed in the pedagogical process.

\section{Conclusion}

Once the results of the study have been identified, it can be concluded that the Conclusions of the study are: The Conclusions of the study are:

1. The EFST technology based on a systemic-practical, personality-oriented and collective approach to learning has supplemented the arsenal of pedagogical technologies to overcome the crisis of 6-7 years and to avoid or reduce the severity of school maladaptation, as it has the following advantages:

- ensures the continuity of activities in the system of pre-school - school; 
- includes the potential of the additional education system to form the physical health of the child as the basis for the success of any activity;

- implies the possibility of communication within the framework of the main activity, the expansion of the social interaction of the child with groups of persons of different ages.

2. The structure of this technology includes the following methods:

- early introduction of sport;

- a flexible system for assessing sports results;

- a method of mastering and manifesting the principles of Olympism;

- the method of problem education;

- didactic game method;

- communicative games;

- development and implementation of the individual educational trajectory of the child;

- a method of interactive and multimedia games in physical education.

Each method has a peculiar effect on increasing the child's stress resistance and other qualities that contribute to the successful adaptation of the child to school.

3. The presented results allow us to conclude that this technology can be applied in elementary school conditions. The prospect of the study is the correction and enrichment the technology with new methods and meaningful content for its application at the turn of primary and secondary schools, which also coincides with the crisis (teenage) period of child development.

In the future, the authors plan to adapt the EFST technology to other crisis periods of development, namely, to transition from elementary school to middle school and to reduce the severity of the manifestations of crisis phenomena of adolescence. For this, the technology will need to be saturated with methods appropriate for the leading activities in the teenage age group.

\section{Recommendations}

The technology developed by the authors, the effectiveness of which was proved in the course of the experimental work, will be useful for parents whose children are at the stage of transition from preschool to school education. The indicated technology can be implemented both in the conditions of an educational institution and within the framework of family education. This work is of value to teachers interested in preserving the health of preschool children and primary school children and in expanding their pedagogical arsenal of technologies and methods aimed at preventing school maladaptation and increasing the readiness of children to school studies. 


\section{References}

Abisheva, M. M. (2014). Role of additional education in formation of socially active personality. Current issues of modern pedagogy: materials V Internunar, 143-145.

Afonaseva, L. A. (2016). Technology “TRIZ” (theory of solving inventive problems) as a factor of development of creative abilities of pre-school students. Problems and prospects of education development: materials VIII International Cont, pp. 98-100.

Alekseeva, I. S. \& Gregory, V. V. (2019). Design of the process of development of educational abilities of younger schoolchildren in the extended day group. Azimuth of Scientific Research: Pedagogy and Psychology, 8(4), 22-24.

Busygina, A. L., Archipova, I. V. \& Firsova, T. A. (2018). Three-factor model of social adaptation of children of primary school age raised in different sociocultural conditions. Azimuth of Scientific Research: Pedagogy and Psychology, 2(23), 351-354.

Bystritskaya, E. V., Grigoryeva, E. L., Lebedkina, M. V., Reutova, O. V., Musin, O. A., Latypov, I. K. \& Petin, D. E. (2019a). Provision of the Continuity of Junior Pupils' Educational Activity by Means of Physical Culture. International Journal of Applied Exercise Physiology, 8(2), 1-8.

Bystritskaya, E. V., Grigoryeva, E. L., Skitnevskiy, V. L., Podlubnaya, A. A. \& Levina, L. M. (2019b). Mechanisms of overcoming school inadaptation of younger schoolchildren in the multiethnic classroom. Journal of Environmental Treatment Techniques, 7(3), 445449.

Dormidontova, L. (2016). Educational and recreational aspects of the use of mobile games in the preschool organization. Pedagogical-psychological and medical-biological problems of physical culture and sports, 11(2), 113-119.

Efimov, N. N. Kiseleva, Y. S. \& Nikitskaya, M. P. (2018). Evristic "immersion" as a means of organizing project and research activities of students. Concept, 10, 77-81.

Gregory, E.L. \& Borisenko, A.G. (2019). Formation of sports and creative infrastructure of small cities and villages on the example of the project "SPARTIAN Academy". Anthropic educational technologies in the field of physical culture collection of articles on the materials of the V All-Russian scientific and practical conference, pp. 262-266. Nizhny Novgorod: Nizhny Novgorod State Pedagogical University, Russia.

Grigoryeva, E. L., Lebedkina, M. V., Musin, O. A., Germanov, G. N. \& Bajmurzin, A. R. (2019). Autodidactic for parents of children studying in multi-ethnic school environment. Humanities and Social Sciences Reviews, 7(5), 719-724.

Joiners, V. I. (2017). Current theoretical and methodological problems of development of "sports science". Fundamental and applied research of physical culture, sports, Olympism: traditions and innovations: materials of the I All-Russian scientific and practical conference on May 24-25, 2017 under the ed. A.A. Peredelskiy, pp. 36-49. 
Moscow: RGUFKSMiT.

Korenkova, O. N. (2015). Use of mobile games and game exercises for comprehensive development of children of older pre-school age in health work in the mode of day. Problems of pedagogy, 2(3), 71-74.

Kozubtsov, I. N. (2018). Designing Pedagogical Technology of Mutual Education in Scientific School "Development of Methodological Culture of Young Scientist". International Journal of Experimental Education, 3, 11-16.

Krylova, A. S. (2017). Psycho-pedagogical aspects of adapting first graders to school. Academy, 1(16), 68-69.

Maltsev, V. P. (2019). Current issues of methodology of formation of culture of life safety of schoolchildren. Azimuth of Scientific Research: Pedagogy and Psychology, 8(4), 130133.

Mukhina, B. C. (1990). Six-year-old at school: A book for a teacher. Moscow: Enlightenment. Neverkovich, S. D., Bystritskaya, E. V., Burkhanova, I. Y., Ivanova, S. S. \& Ignatyeva, E. V. (2019). Principles and technologies of improving the educational autonomy of students in the conditions of two-level education. Humanities and Social Sciences Reviews, 7(4), $1180-1188$.

Runova, T. A. Gutsu, E. G. \& Nyagolova, M. D. (2019). Study on the Development of Educational Cooperation between Junior Schoolchildren. Vestnik of Minin University, $7(3), 12-22$.

Schlykova, D. V. (2015). Problems of school adaptation. Journal of Nizhny Novgorod University named after N.I. Lobachevsko. Series: Social sciences, 4(40), 11-121.

Selevko, G. K. (2005). Encyclopedia of educational technologies. Moscow: People 's Education.

Sergei, B. V. (2016). Conditions of formation of environmental knowledge of junior schoolchildren. Young scientist, 9, 113-123.

Tymaseva, Z. I. \& Orekhova, I. L. (2019). Family environment as a means of preserving, promoting the health of learners and forming self-preservation behavior. Vestnik of Minin University, 7(3), 5-13.

Talebi, S., \& Nejad, P. I. (2019). Comparing the Descriptive Assessment in terms of Critical and Creative Thinking among the Sixth Grade Students in the Public and Private Schools. Journal of Social Sciences and Humanities Research, 7(02), 6-14.

Voronkina, M. A. (2016). Specifics of disadaptation in junior school age. Journal of Taganrog Institute named after A.P. Chekov, 1, 176-180.

Vahedi, M., \& Arvand, H. (2019). The Role of Information Systems in Decision-making and Public Policy Making. Journal of management and accounting studies, 7(02), 11-14. 